\title{
Randomized control trial comparing the functional outcomes of dynamic hip screw and locking plate dynamic hip screw in intertrochanteric fractures of femur
}

\author{
Kiran Ramachandran, Dileep Sasidharan*, Oommen Mathew
}

Department of Orthopaedics, Pushpagiri Institute of Medical Sciences and Research Centre, Thiruvalla, Kerala, India

Received: 16 February 2020

Revised: 05 March 2020

Accepted: 09 March 2020

*Correspondence:

Dr. Dileep Sasidharan,

E-mail: drdileepsasi@gmail.com

Copyright: () the author(s), publisher and licensee Medip Academy. This is an open-access article distributed under the terms of the Creative Commons Attribution Non-Commercial License, which permits unrestricted non-commercial use, distribution, and reproduction in any medium, provided the original work is properly cited.

\begin{abstract}
Background: The objective of the study was to compare the functional outcomes of intertrochanteric fractures of the femur treated with dynamic hip screw (DHS) and locking plate DHS in elderly.

Methods: 48 participants (23 in DHS and 25 in locking plate DHS) aged $\geq 50$ years with intertrochanteric fracture of femur were enrolled in the present randomized open label parallel group trial conducted at Pushpagiri Institute of Medical Sciences and Research Centre during a period of 1 year. Open, pathological, other fractures in the same limb and participants with neurological involvement were excluded. Standard of care (pre and post-operative care) was given to all participants. Sociodemographic, radiological findings, fracture type and Singh's index were recorded at baseline, 6 weeks, 3 and 6 months. Study commenced after approval from Institutional Ethics Committee and written informed consent was obtained from all study participants. Participants were randomized in 1:1 ratio using coin flip method. Quantitative variables were expressed means and medians and qualitative variables were expressed as proportions. Tests of significance were independent sample t test, Mann Whitney U test, Friedman test and Chi square test.

Results: Between DHS and locking plate DHS, no significant difference in baseline parameters, neck shaft angle, tip apex distance, shortening, Harris hip score, range of motion score and length of hospital stay were observed.

Conclusions: The functional outcomes and complications between DHS and locking plate DHS were not significantly different.
\end{abstract}

Keywords: DHS, Locking plate DHS, Intertrochanteric fractures, Osteoporosis

\section{INTRODUCTION}

The increasing incidence of proximal femur fractures over the past few decades is attributed to the higher proportion of ageing population. Hip fractures are common among individuals over 60 years and the most common etiology is fall. As age advances from 65 to 80 years the proportion of elderly who fall at least once a year rises from 30 to $50 \%$. $^{1}$ Hip fractures contribute significantly to health care expenditure since they almost always require surgical intervention and the need for anatomical union or replacement with prosthesis for preservation of function. Treatment aims at avoiding complications of recumbency and immobilization and complications that arise due to the deforming forces on the fracture site and compromised bone quality due to osteoporosis. Dynamic hip screw (DHS) is the most commonly used extramedullary device for intertrochanteric fractures and has become the standard of care for the same and has reasonable results. ${ }^{2-4}$ It provides stable fixation and allow early mobilization since it enables optimal collapse and compression of the fracture site. Due to the lack of evidence of superiority or non- 
inferiority of intramedullary hip screws for intertrochanteric fracture fixation, especially unstable ones, DHS remains the standard of care though the best treatment option in unstable intertrochanteric fractures remain a matter of controversy. ${ }^{5}$ Obtaining a secure fixation of an implant to osteoporotic bone due to reduced cortical and cancellous bone for the screw threads to gain purchase thereby reducing the pullout strength of the implant remains a challenge in treating intertrochanteric fractures in elderly. The two most common modes of failure of DHS is the screw cut out from the head and pull out of the side plate from the shaft. Locking plate technology was invented to provide increased pullout strength to the plate construct from osteoporotic bone by fixing the screw head to the plate. Biomechanical studies have proven the superiority the locking DHS over ordinary DHS in terms of pull out strength of the side plate. There is a paucity of clinical studies comparing these devices in the English literature. The present study aims at comparing the functional outcomes (effectiveness and complications) of intertro-chanteric fractures treated with dynamic hip screw and locking dynamic hip screw especially in osteoporotic bone.

\section{METHODS}

The present randomized open label parallel group trial enrolled 48 participants aged 50 years or above with intertrochanteric fracture of the hip joint presenting to Emergency department or Department of Orthopaedics of Pushpagiri Institute of Medical Sciences and Research Centre, Thiruvalla, Kerala in a time period between October 2012 and May 2013. Participants with open fractures, pathological fractures, neurological involvement and other fractures in the same limb were excluded. Four participants lost to follow up and six participants died in the immediate post-operative period due to problems unrelated to fracture and were excluded from analysis. Initial assessment of study participants was done in the Emergency Department for associated injuries and standard anteroposterior and lateral radiographs were taken after administering adequate analgesia. All participants were given above knee non adhesive traction and admitted for surgery and standard operative procedures were used for surgery. Sociodemographic parameters, findings of clinical examination, radiological findings were recorded in case record forms. Boyd and Griffin classification was used for categorizing fractures and stability of fractures were assessed using Evan's classification. Study commenced after approval from Institutional Ethics Committee (No: PIMS\& RC/E1/388A/ 83/12) and written informed consent was obtained from all study participants. Participants were randomized (stratified randomization) using coin flip method after assessing severity of osteoporosis using Singh index at 1:1 ratio to ordinary DHS or locking plate DHS under general or spinal anaesthesia after single dose cefuroxime 1.5 gram intravenous after test dose. Post operatively participants received parenteral cefuroxime $750 \mathrm{mg}$ three times daily post operatively both groups received standard antibiotic and thromboembolism prophylaxis. Study data was assessed by direct interview and medical records and Xray at the time of admission and follow up. Implant position was assessed on the first post-operative day using radiograph, wounds were inspected and drain was removed on the second post-operative day. Participants were mobilised in bed and partial weight bearing was initiated in the immediate postoperative period based on pain tolerance of patients and the protocol was standardized irrespective of the implant used. Follow up evaluation was done at 6 weeks, 3 months and 6 months after intervention and the adequacy of callus formation, implant position by tip apex distance (TAD) and neck shaft angle (NSA) using anteroposterior and lateral plain radiographs. Partial to full weight bearing was started depending on clinical and radiological evaluation and the functional outcome at 6 months were evaluated using Harris hip score. Normality of distribution was assessed using Shapiro Wilk test and normally distributed quantitative variables are expressed mean (standard deviation (SD)) and non-normally distributed quantitative variables are expressed as median (interquartile range (IQR)). Qualitative variables are expressed as proportions and frequency. Tests of significance were independent sample t test, Mann Whitney U test, Friedman test and Chi square test.

\section{RESULTS}

The mean age of the study participants was 79 years and $68.4 \%$ were females. Baseline parameters of the study participants are demonstrated in Table 1 and the participant enrolment details are demonstrated in figure 1. The mean age was comparable between male 76.4 (3.5) and female participants $80.2(1.2)(\mathrm{p}=0.2) .47 .4 \%(\mathrm{n}=18)$ participants were in the age group 80-89 years. Trivial injury was the cause of fracture in $97.4 \% \quad(n=37)$ participants and road traffic accident was the etiology in the rest $(n=1)$. There was no significant difference in the cause of injury between treatment groups. Between treatment groups, no significant difference in preinjury walking status $(\mathrm{p}=0.7)$ and the side of injury $(\mathrm{p}=0.7)$ was observed. No significant difference in comorbidities was observed between treatment groups. 27 (71.1\%) participants underwent spinal anaesthesia of which 13 (48.1\%) were in DHS group and $14(51.9 \%)$ in the locking plate DHS group.

The proportion of participants with bone quality according to Singh's index is demonstrated in Table 2. The median implant angle among study participants was $135^{\circ}\left(130^{\circ}\right.$ $\left.135^{\circ}\right)$ and in the participants who underwent DHS was $135^{\circ}\left(130^{\circ}-135^{\circ}\right)$ and among participants who underwent locking plate DHS was $135^{\circ}\left(135^{\circ}-135^{\circ}\right)$ and was not significantly different from each other $(\mathrm{p}=0.4)$.

The NSA at immediate post-operative period, 6 weeks, 3 months and 6 months post-operative period is demonstrated in Table 3. The comparison of TAD among study participants and treatment groups is demonstrated in 
Table 4. Comparison of outcomes between treatment groups at 6 months is demonstrated in Table 5. Superficial infection in the immediate post-operative period was observed in one participant who underwent DHS which was controlled by antibiotics. Majority of the study participants had good range of movements post operatively except 3 participants ( 2 in DHS and 1 in locking plate DHS) who were bedridden. No significant difference in proportion of participants who had shortening (Table 6) and in Harris hip score was observed (Table 7).

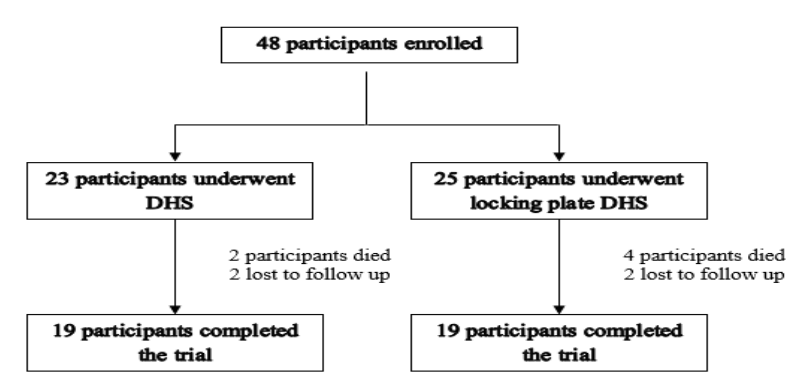

Figure 1: Participant enrolment in the study.

*The causes of death were not directly related to their hip fractures.

Table 1: Baseline parameters of the study participants.

\begin{tabular}{|llll|}
\hline Parameter & Total & DHS & Locking plate DHS \\
\hline Mean age (SEM) & $\mathbf{N}(\boldsymbol{\%})$ & $\mathbf{N}(\%)$ & $\mathbf{N}(\boldsymbol{\%})$ \\
\hline Female gender -\% & $79(1.4)$ & $78(1.9)$ & $80(2)$ \\
\hline Median days of injury to admission (IQR) & $26(68.4)$ & $12(63.2)$ & $14(73.7)$ \\
\hline Median days of admission to surgery (IQR) & $0(0-1)$ & $0(0-1)$ & $0(0-1)$ \\
\hline Median days from surgery to discharge (IQR) & $2(2-3)$ & $2(2-3)$ & $2(2-3)$ \\
\hline Boyd \& Griffin type II fracture (\%) & $23(10.8-11)$ & $11(10-11)$ & $11(11-11)$ \\
\hline Evans classification - unstable (\%) & $25(65.8)$ & $11(57.9)$ & $12(63.2)$ \\
\hline Closed reduction $(\%)$ & $34(89.5)$ & $11(57.9)$ & $14(73.7)$ \\
\hline
\end{tabular}

No significant difference was observed between groups.

Table 2: Bone quality of participants according to Singh's index.

\begin{tabular}{|lll|}
\hline Singh index & DHS $(\mathbf{n = 1 9 )}$ & Locking plate DHS $(\mathbf{n}=\mathbf{1 9})$ \\
\hline Grade 1 & $\mathbf{N}(\mathbf{\%})$ & $\mathbf{N}(\mathbf{\%})$ \\
\hline Grade 2 & $0(0)$ & $0(0)$ \\
\hline Grade 3 & $1(5.2)$ & $3(15.7)$ \\
\hline Grade 4 & $10(52.6)$ & $11(57.9)$ \\
\hline Grade 5 & $8(42.1)$ & $4(21)$ \\
\hline
\end{tabular}

No significant difference was observed between groups $(\mathrm{p}=0.3)$.

Table 3: Implant angle and NSA among study participants.

\begin{tabular}{|lllll|}
\hline Group & $\begin{array}{l}\text { Median post- } \\
\text { operative NSA } \\
(\text { IQR })\end{array}$ & $\begin{array}{l}\text { Median NSA at 6 } \\
\text { weeks (IQR) }\end{array}$ & $\begin{array}{l}\text { Median NSA at 3 } \\
\text { months (IQR) }\end{array}$ & $\begin{array}{l}\text { Median NSA at 6 } \\
\text { months (IQR) }\end{array}$ \\
\hline Study participants $(\mathbf{n = 3 8})^{*}$ & $135(135-140)$ & $135(135-140)$ & $135(135-140)$ & $135(135-140)$ \\
\hline DHS $(\mathbf{n = 1 9 )}$ & $135(135-140)$ & $135(135-140)$ & $135(135-140)$ & $135(135-138)$ \\
\hline Locking plate DHS $(\mathbf{n = 1 9})^{\mathrm{I}}$ & $138(135-140)$ & $138(135-140)$ & $138(135-140)$ & $138(135-140)$ \\
\hline
\end{tabular}

*,, , Iindicates no significant difference was observed between the groups $(\mathrm{p}=0.8),(\mathrm{p}=0.8),(\mathrm{p}=0.4)$ respectively.

Table 4: TAD among study participants.

\begin{tabular}{|llll|}
\hline Mean TAD (SEM)- cms & All participants $(\mathbf{n}=\mathbf{3 8})^{*}$ & DHS $(\mathbf{n}=\mathbf{1 9})^{\Gamma}$ & Locking plate DHS $(\mathbf{n}=\mathbf{1 9})^{[}$ \\
\hline Post-operative & $1.57(0.06)$ & $1.67(0.1)$ & $1.46(0.07)$ \\
\hline 6 weeks & $1.56(0.6)$ & $1.67(0.1)$ & $1.45(0.07)$ \\
\hline 3 months & $1.54(0.6)$ & $1.66(0.1)$ & $1.42(0.07)$ \\
\hline 6 months & $1.49(0.6)$ & $1.61(0.1)$ & $1.38(0.08)$ \\
\hline
\end{tabular}

*indicates significant difference of postoperative TAD compared to 3 months $(\mathrm{p}=0.03)$ and 6 months $(<0.001)$, ${ }^{\text {indicates significant }}$ difference of TAD at 6 months compared to post-operative (0.006), 6 weeks $(0.006)$ and 3 months $(0.012)$, "indicates significant difference of TAD at 6 months compared to post-operative (0.01), 6 weeks $(0.02)$ and 3 months $(0.049)$. 

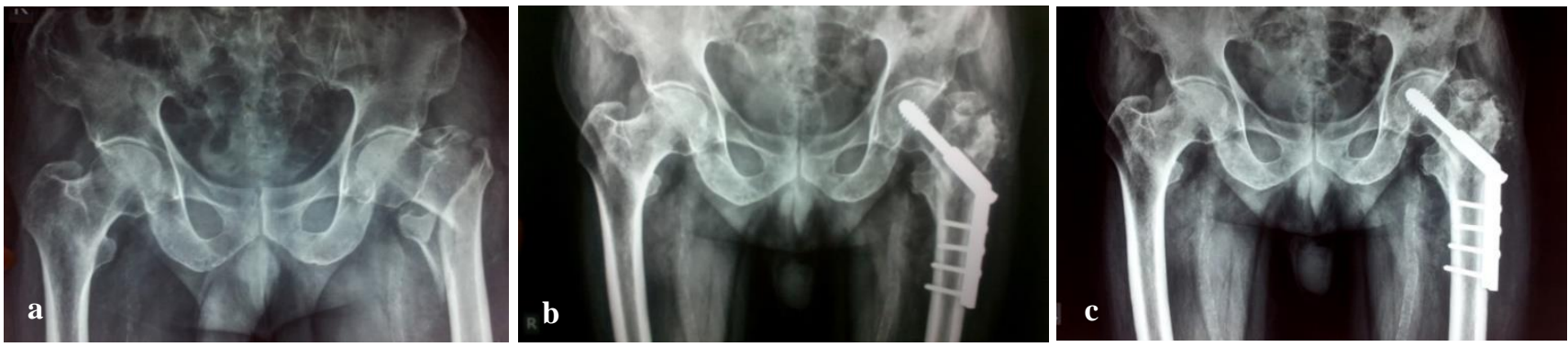

Figure 2: (a) Radiological assement of a participant at baseline who underwent DHS, (b) radiological assement of a participant at 3 months postoperative after fixation with DHS, (c) radiological assement of a participant at 6 months postoperative after fixation with DHS.
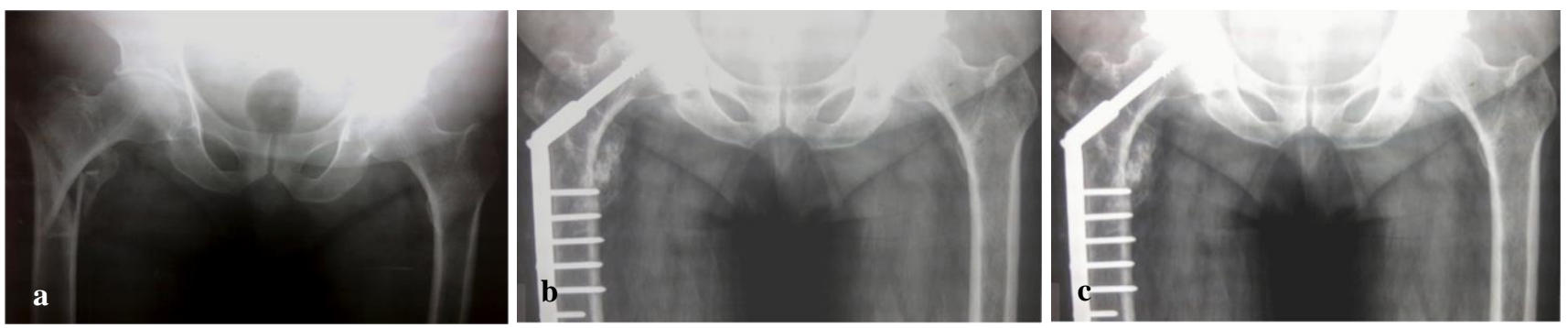

Figure 3: (a) Radiological assessment of a participant who underwent locking plate DHS at baseline,

(b) radiological assessment of a participant who underwent locking plate DHS 3 months post operatively,

(c) radiological assessment of a participant who underwent locking plate DHS 6 months post operatively.

Table 5: Clinical evaluation at 6 months.

\begin{tabular}{|lll|}
\hline Clinical evaluation & $\begin{array}{l}\text { Ordinary } \\
\text { DHS }\end{array}$ & $\begin{array}{l}\text { Locking } \\
\text { plate DHS }\end{array}$ \\
\hline Shortening at 6 months* & $1(0-1)$ & $0.8(0-1)$ \\
\hline Range of motion score* & $4(4-5)$ & $4(4-5)$ \\
\hline Harris hip score* & $86(72-91)$ & $86(70-91)$ \\
\hline Length of hospital stay $^{*}$ & $13(12-15)$ & $14(13-15)$ \\
\hline
\end{tabular}

*indicates no significant difference in shortening at 6 months $(\mathrm{p}=0.9)$, range of motion score $(\mathrm{p}=0.7)$, Harris hip score $(\mathrm{p}=1)$ and length of hospital stay $(\mathrm{p}=0.1)$.

Table 6: Shortening at 6 months.

\begin{tabular}{|lll|}
\hline Shortening in cm & $\begin{array}{l}\text { Ordinary } \\
\text { DHS }\end{array}$ & $\begin{array}{l}\text { Locking } \\
\text { plate DHS }\end{array}$ \\
\hline N (\%) & N (\%) \\
\hline No shortening & $7(36.8)$ & $6(31.6)$ \\
\hline$<\mathbf{2}$ & $11(57.9)$ & $13(68.4)$ \\
\hline $\mathbf{2 - 2 . 9}$ & $1(5.3)$ & 0 \\
\hline$>\mathbf{3}$ & 0 & 0 \\
\hline
\end{tabular}

No significant difference was observed between groups $(\mathrm{p}=0.5)$.

Table 7: Harris hip score at 6 months.

\begin{tabular}{|lll|}
\hline Harris hip score & $\begin{array}{l}\text { Ordinary } \\
\text { DHS }\end{array}$ & $\begin{array}{l}\text { Locking } \\
\text { plate DHS }\end{array}$ \\
\hline Excellent $(\mathbf{9 0 )}$ & $8(42.1)$ & $\mathbf{N}(\%)$ \\
\hline Good $(\mathbf{8 0 - 8 9 )}$ & $4(21.1)$ & $5(26.4)$ \\
\hline Fair $\mathbf{( 7 0 - 7 9 )}$ & $3(15.8)$ & $1(5.2)$ \\
\hline Poor $(\mathbf{6 0 - 6 9 )}$ & $2(10.5)$ & $3(15.8)$ \\
\hline Bedridden & $2(10.5)$ & $1(5.2)$ \\
\hline
\end{tabular}

No association was observed between groups $(\mathrm{p}=0.8)$.
All the patients had TAD less than $2.5 \mathrm{cms}$. There was no screw cut out, implant breakage or plate lift off. Radiological assessment of NSA and TAD at 6 weeks, at 3 months and 6 months did not show any difference in both groups. The radiographs of participant who underwent DHS at baseline, 3 months and 6 months are demonstrated in Figures 2 a-c respectively and that of participant who underwent locking plate DHS at baseline, 3 months and 6 months are demonstrated in Figures 3 a-c respectively.

\section{DISCUSSION}

Current evidence suggests internal fixation with early ambulation in intertrochanteric fractures to reduce the morbidity and mortality, but controversy exists in the type of implant to be used especially in osteoporotic fractures. Even though DHS is considered as the standard in surgical fixation of theses fractures, fixation failure by cut out of the screw from head and plate lift of from the shaft are not rare. Locking screws through the plate gives more pullout strength to the construct and can help with one of the mechanisms of failure. Hence the present study comparing the functional outcomes of locking plate DHS and ordinary DHS was conducted.

$68.4 \%$ participants were females, intertrochanteric fractures are commonly reported in females and the incidence increases with increase in age. ${ }^{6}$ The mean age of the study participants was 79 years which was significantly higher than previous reports from North India with mean age of 66.5 years and 62 years and was comparable to previous study from Kerala which reported an age of 77 years. ${ }^{7-9}$ This difference in age could be attributable to the 
higher awareness of post-menopausal osteoporosis among Keralites. The mean age was comparable between male and female participants. The etiology of the majority of fractures was due to domestic fall $(97 \%)$ which has been previously described in individuals aged 50 and above. The common side involved was right and type II Boyd and Griffin $(60.5 \%)$ fractures was the commonest type encountered which is similar to previous reports. ${ }^{10}$ Maximum proportion of participants were having grade III or IV osteoporosis assessed by Singh's index and was comparable to previous studies. ${ }^{11}$ All participants had a post-operative tip apex less than $2.5 \mathrm{~cm}$ and only one participant had complication (shortening more than 2.5 $\mathrm{cm}$ ) which could indicate the correct placement of head screw in our patients. Participants underwent surgery within 4 days of admission which can be substantiated by the previous reports of no difference in mortality and in hospital stay between participants who underwent surgery within 8 and 48 hours of admission indicating that the emergency surgical procedure is not necessary. ${ }^{12}$ For ensuring better functional outcomes, pre and postoperative evaluation were done using radiographs in our study. The post-operative infection rates were lower $(2.6 \%)$ compared to previous reports of $3-5 \% .^{13}$

The goal of surgical treatment is strong stable fixation of the fragments and it depends on bone quality, fragment geometry, reduction, implant design and implant placement. Most patients with intertrochanteric fracture have considerable osteopenia reducing the purchase of fixation and it is recommended to place the head of the screw in the head and neck where the bone quality is best. The quality of the bone varies from quadrant to quadrant due to the anatomy of the calcar. There has been difference in opinion regarding the positioning of screws, we placed the screws centrally or inferiorly on anteroposterior view and centrally on lateral view. No cut through was observed in our study though it has been reported to be between $16.8-53 \% .^{14,15}$

The TAD i.e. the sum of the distance from the tip of the screw to the apex of the femoral head on anteroposterior and lateral views of less than $25 \mathrm{~mm}$ reduces the mechanical failure by cut out of screw from head. All study participants had TAD less than $25 \mathrm{~mm}$. No significant change in TAD and NSA was observed during follow up for both groups indicating lower chances of varus deformities.

Instability of fracture fixation leads to shortening due to posterior collapse and varus of NSA, due to increasing retroversion of the neck. Fixation appliance extrudes out through the head into the acetabulum in shortening especially with fixed nail plate devices such as Jewett nail plate or enders pins. Shortening is uncommon with DHS especially if the lag screw has enough space in the barrel for sliding. Varus and retroversion typically result in screw cutting through the anterosuperior part of the head, or appliance breakage at the screw plate junction or plate pulling away from the shaft of the femur if the plate does not break.

Post-operative mobilization in majority of patients was started within 4 days of fixation and was not different among treatment groups $(\mathrm{p}=0.8)$. Partial weight bearing was started within 1week and full weight bearing was initiated within 7 weeks. Days to partial weight bearing $(\mathrm{p}=0.7)$, full weight bearing $(\mathrm{p}=0.8)$ and time to fracture union $(\mathrm{p}=0.2)$ were comparable in the treatment groups. Two and one participants in DHS and locking plate DHS respectively were bedridden due to associated medical complications. Shortening was also comparable between the treatment groups. The post-operative Harris hip score was comparable between treatment groups and was comparable with previous studies. Providing secure purchase in severely osteoporotic bone has been described as the theoretical advantage of locking plate, but we did not observe any superiority of locking plate fixation compared to ordinary DHS even in severely osteoporotic bone in terms of functional outcome and complications. The lower rates of failure depend on the TAD and not by reduced plate lift off which is reduced by locking plate DHS. Published literature has also demonstrated that the use of 2 bicortical screws were associated with reduced plate lift off and some have demonstrated that the quality of bone did not make any significant difference in the outcomes or complications of intertrochanteric fractures.

\section{Limitations}

Small sample size and not using bone densitometry were the major pitfalls of the study.

\section{CONCLUSION}

Intertrochanteric fractures were common in females and in those aged between 70 to 90 years. Intertrochanteric fractures treated with DHS and locking plate DHS were not significantly different from each other in functional outcomes or complications.

\section{Funding: No funding sources}

Conflict of interest: None declared

Ethical approval: The study was approved by the institutional ethics committee

\section{REFERENCES}

1. Stalenhoef P, Crebolder H, Knottnerus J, Horst F. Injuries. Incidence, risk factors and consequences of falls among elderly subjects living in the community. A criteria-based analysis. Eur J Public Health. 1997;7:328-34.

2. Lyons AR. Clinical outcomes and treatment of hip fractures. Am J Med. 1997;103(2):51-63.

3. McLoughlin SW, Wheeler DL, Rider J, Bolhofner B. Biomechanical evaluation of the dynamic hip screw with two- and four-hole side plates. J Orthop Trauma. 2000;14(5):318-23. 
4. Bolhofner BR, Russo PR, Carmen B. Results of intertrochanteric femur fractures treated with a 135degree sliding screw with a two-hole side plate. J Orthop Trauma. 1999;13(1):5-8.

5. Simpson AH, Varty K, Dodd CA. Sliding hip screws: modes of failure. Injury. 1989;20(4):227-31.

6. Tanner DA, Kloseck M, Crilly RG, Chesworth B, Gilliland J. Hip fracture types in men and women change differently with age. BMC Geriatr. 2010;10:12.

7. Rath S, Yadav L, Tewari A, Chantler T, Woodward M, Kotwal P, et al. Management of older adults with hip fractures in India: a mixed methods study of current practice, barriers and facilitators, with recommendations to improve care pathways. Arch Osteoporos. 2017;12(1).

8. Ahuja K, Sen S, Dhanwal D. Risk factors and epidemiological profile of hip fractures in Indian population: A case-control study. Osteoporos Sarcopenia. 2017;3(3):138-48.

9. Paul P, Issac RT. Delay in time from fracture to surgery: A potential risk factor for in-hospital mortality in elderly patients with hip fractures. J Orthop. 2018;15(2):375-8.

10. Boyd HB, Griffin LL. Classification and treatment of trochanteric fractures. Arch Surg. 1949;58(6):85366.
11. Lee Y-S, Huang H-L, Lo T-Y, Huang C-R. Dynamic hip screw in the treatment of intertrochanteric fractures: a comparison of two fixation methods. Int Orthop. 2007;31(5):683-8.

12. Dolk T. Operation on hip fracture patient Analysis of the time factor. Injury. 1990;21:369-92.

13. Kyle RF, Gustilo RB, Premer RF. Analysis of six hundred and twenty-two intertrochanteric hip fractures. J Bone Joint Surg Am. 1979;61(2):216-21.

14. Davis TR, Sher JL, Horsman A, Simpson M, Porter BB, Checketts RG. Intertrochanteric femoral fractures. Mechanical failure after internal fixation. J Bone Joint Surg Br. 1990;72(1):26-31.

15. Jensen JS, Tøndevold E, Sonne-Holm S. Stable trochanteric fractures. A comparative analysis of four methods of internal fixation. Acta Orthop Scand. 1980;51(5):811-6.

Cite this article as: Ramachandran $\mathrm{K}$, Sasidharan D, Mathew O. Randomized control trial comparing the functional outcomes of dynamic hip screw and locking plate dynamic hip screw in intertrochanteric fractures of femur. Int J Res Orthop 2020;6:525-30. 